\title{
Das Jesusgebet in der orthodoxen Spiritualität
}

Erich Bryner

\section{Ein kurzes, formelhaftes Gebet intensiv beten}

Uralte Fragen in der christlichen Gebetspraxis lauten:»Wie soll man beten? " Was soll man beten? Bereits der Apostel Paulus rang um diese Fragen, wenn er im Römerbrief schrieb: "Wir wissen nicht, was wir beten sollen, wie sich's gebührt; aber der Geist selber tritt für uns ein mit unaussprechlichem Seufzen" (Röm 8,26). Diese Fragen beschäftigten auch die Wüstenväter in Ägypten im 3./4. Jahrhundert sehr stark. Sehr bekannt ist die Vision des Antonius: Er sei eines Tages in verdriesslicher Stimmung gewesen, habe einen Engel gesehen, "der sass und arbeitete, stand dann von der Arbeit auf, betete, setzte sich wieder, flocht an seinem Seil weiter und erhob sich abermals zum Gebet. « ${ }^{1}$ Der Engel soll Antonius daraufhin gesagt haben: "Mach es ebenso, und du wirst das Heil erlangen." Der Rhythmus von Gebet und Arbeit ist hier programmatisch formuliert, im späteren Mönchtum wurde daraus die Formel ora et labora.

Was sollen nun Form und Inhalt des Gebets sein? Die Wüstenväter antworteten oft: Man solle nicht viele Worte machen, sondern ein kurzes, formelhaftes Gebet intensiv beten und dabei den Namen Jesu ständig anrufen.

In den Sprüchen der Wüstenväter, den Apophthegmata patrum, finden sich wichtige Hinweise auf diese Gebetspraxis: Abbas Makarios (ca. 300-380/90), ursprünglich ein ägyptischer Kameltreiber, der mit etwa dreissig Jahren Einsiedler in der Wüste wurde und sich mit ca. vierzig Jahren zum Priester weihen liess, antwortete auf die Frage, was man beten solle: Man solle nicht viele Worte machen (nach Matth 6,7 "nicht plappern wie die Heiden«), sondern nur kurze, formelhafte Gebete beten, wie: "Herr, wie du willst und weisst, erbarme dich!" Oder: »Herr, hilf! «

Sein Zeitgenosse Abbas Lukios erklärte, wie er zu seiner Handarbeit betet und dabei den Rhythmus von Gebet und Arbeit pflegt:

1 Abbas Antonius, Apophthegma 1, zit. aus: Weisungen der Väter. Apophthegmata patrum, auch Gerontikon genannt, übersetzt von Bonifaz Miller (= Sophia. Quellen östlicher Theologe 6), Trier, ${ }^{4} 1998,15$.

2 Abbas Makarios, Apophthegma 472, Weisungen derVäter, 168. 
"Trotz der Verrichtung meiner Handarbeit bete ich unablässig«, entsprechend der Ermahnung des Apostels Paulus: BBetet ohne Unterlass!« (1.Thess 5,17). Und er schrieb:»Ich setze mich mit Gott nieder, weiche meine Palmfasern ein und flechte sie zu einem Seil. Dabei sage ich: `Erbarme dich meiner, o Gott, in deinem grossen Erbarmen, und nach der Menge deiner Erbarmungen wasche ab meine Ungerechtigkeiten «. Abbas Lukios pflegte also bei der einförmigen und rhythmischen Handarbeit unablässig zu beten. ${ }^{3}$

Nicht nur Einsiedler und Mönche übten diese Gebetspraxis aus, auch gottesfürchtige Laien mitten in der Welt taten es, wie ein Ausspruch des Antonius zeigt: Er berichtete von einem Arzt, der in der Stadt seinem Beruf nachgeht und den ganzen Tag einen Hymnus aus der orthodoxen Liturgie singt, das "Trishagion" (»Heiliger Gott, Heiliger Starker, Heiliger Unsterblicher, erbarme dich unser«). ${ }^{4}$

Zu den kurzen Gebetsformeln kamen die ausdrückliche Anrufung Jesu Christi und die Bitte um sein Erbarmen. Auch dies gehörte zu den ständigen und andauernden Gebeten. Biblische Ansatzpunkte waren der Ausruf eines Blinden in der Nähe von Jericho: "Jesus, Sohn Davids, hab Erbarmen mit mir!" (Luk 18,38) sowie das Gebet des Zöllners im Tempel zu Jerusalem »Gott, sei mir Sünder gnädig!« (Luk 18,13). Daraus entwickelte sich in der Folgezeit das sog. Jesusgebet oder Herzensgebet. Der bereits erwähnte Abbas Makarios ermahnte: "Denke mit Inbrunst an die Anrufung >Herr Jesus Christus, erbarme dich meiner «. Eine bessere Betrachtung als die Anrufung des $\mathrm{Na}$ mens unseres Herr Jesus Christus gebe es gar nicht. Daher gelte es, bei jedem Atemzug zu sprechen: "Herr,Jesus Christus, erbarme dich meiner; ich preise dich, mein Herr Jesus, eile, mir zu helfen. " ${ }^{5}$

\section{Das Jesusgebet}

Im Laufe des 5. Jahrhunderts entstand das Jesusgebet oder Herzensgebet. Seine klassische Formulierung lautet:

"Herr Jesus Christus, Sohn Gottes, erbarme dich meiner«, manchmal mit dem Zusatz »des Sünders». Im griechischen Urtext: »Kyrie Iesou Christe, hye theou, eleēson eme«, in der kirchenslawischen Übersetzung: "Gospodi Iisuse, syn božij, pomiluj mja.»

3 Abbas Lukios, Apophthegma 446, Weisungen derVäter, 156.

Abbas Antonius, Apophthegma 24, Weisungen derVäter, 21.

5 Zit. aus: Kleine Philokalie. Belehrungen der Mönchsväter der Ostkirche über das Gebet. Ausgewählt u. übersetzt v. Mattias Dietz, eingeleitet v. Igor Smolitsch, Zürich 1976, 29 f. 
Diese Gebetsformel wurde zum ersten Mal von Diadochus von Photike gelehrt. Diadochus von Photike lebte und wirkte in der Mitte des 5. Jahrhunderts (gest. vor 486), war von 451 an Bischof der Eparchie Photike in Epirus, Nordgriechenland. Sein Hauptwerk, eine Hundertspruchlehre über das Thema "Geistliche Vollkommenheit«, zeichnet sich durch eine ausserordentliche Prägnanz in der Gedankenführung und in den Formulierungen aus und hatte einen grossen Einfluss auf die Spiritualität in den Klöstern Griechenlands und weit darüber hinaus. Diadochus hatte sich mit verschiedenen Charismatikern in seiner Umgebung auseinanderzusetzen, deren Glaube nicht in allen Punkten mit der herkömmlichen Orthodoxie übereinstimmte. Er bemühte sich, sie in die Orthodoxie zurückzuholen. Das Jesusgebet war für ihn ein Weg, in die Stille und zu einer tiefen Gotteserfahrung zu kommen.

In seiner Hundertspruchlehre hielt Diadochus fest: "Wenn wir das Bemühen des Verstandes durch die Gegenwart Gottes festgelegt haben, dann verlangt er unbedingt nach einer Tätigkeit, die seinem Eifer entspricht. Man muss ihm das Gebet `Herr ist Jesus` als einzige Beschäftigung geben, die dann vollständig seinem Streben entspricht. Niemand kann ja sagen `Herr ist Jesus` ausser im Heiligen Geist. Wer nicht mit äusserster Strenge dieses Wort in seinem Inneren erwägt, kann Täuschungen nicht entgehen. Wer ohne Unterlass diesen heiligen und glorreichen Namen aus tiefstem Gemüte anruft, wird eines Tages auch das Licht seines Verstandes schauen. $«^{6}$ Diadochus stellte die Kurzformel "Kyrios Iesus " aus 1. Kor 12,3 in den Zusammenhang seiner Erörterungen über das Jesusgebet. Es ist eine kurze, einprägsame Formel, die ständig wiederholt werden kann, ein Stossgebet, das aus einfachen Worten besteht und Wortschwall oder Wortreichtum meidet. Die Wüstenväter haben das einfache Gebetswort im Rhythmus ihrer einfachen, monotonen Handarbeit wie dem Flechten von Seilen oder Körben ständig wiederholt.

Nochmals Diadochus: "Wenn ein Mensch Fortschritte macht in der Beobachtung der Gebote und in dem ständigen Jesusgebet, ergreift das Feuer der heiligen Gnade auch immer mehr die äusseren Sinne seines Herzens. " Diadochus war Mystiker, was aus diesen Worten deutlich hervorgeht, seine Theologie war eine Gnadentheologie.

Dabei darf es dem Betenden nicht allein auf die äusserliche Haltung ankommen. Schon der Wüstenvater und Origenes-Schüler Evagrius Ponticus (345-399) hatte Jahrzehnte zuvor festgestellt, dass

\footnotetext{
Ebd., 54.

Ebd., 60.
} 
es beim Gebet nicht allein auf die Form ankomme, sondern dass man mit innerer Bereitschaft für die geistige Dimension beten solle. Demut und Ergebenheit in den Willen Gottes seien von zentraler Bedeutung: "Bete nicht darum, dass deine Wünsche in Erfüllung gehen, denn sie stehen nicht unbedingt im Einklang mit dem Willen Gottes. Bete vielmehr, wie du gelernt hast: ।Es geschehe dein Wille an mir (vgl. Matth 6,10b). Denn Gott will in allen Dingen das Gute und das was für deine Seele das Richtige ist. Du selber aber strebst nicht gänzlich danach." Und ausserdem: »Das Gebet ist der Aufstieg des Geistes zu Gott. $\|^{8}$

Hesychios, der im 7./8. Jahrhundert lebte und einen grossen Teil seines Lebens als Mönch bzw. Abt im Batos-Kloster (DornbuschKloster) auf der Halbinsel Sinai verbrachte, verfasste ebenfalls Spruchlehren über das Gebet. Das Jesusgebet wurde von ihm hoch geschätzt und intensiv praktiziert. Aus reicher geistlicher Erfahrung teilte er wichtige Beobachtungen mit: "Die Aufmerksamkeit ist die dauernde Ruhe des Gemüts, die keinen anderen Gedanken kennt als immer 'Jesus Christ, Sohn Gottes ‘ auszusprechen [...]. Die Seele wird durch die ununterbrochene Anrufung Christus finden, der das Innere des Herzens erforscht. [...] Das ständige Jesusgebet, vereint mit einer glühenden Sehnsucht, lässt infolge der strengen Wachsamkeit den weiten Raum des Gemütes überströmen von Frieden und Freuden. $\ll^{9} \mathrm{Er}$ forderte seine Schüler und seine Leser dazu auf, jeden Augenblick das Jesusgebet zu beten. "Mit inbrünstigem Gemüt wollen wir es beten, um immer mit dem heiligen Namen Jesu vereint zu bleiben. ${ }^{10}$ Wie es unmöglich sei zu leben, ohne zu atmen, so sei es unmöglich, ohne demütiges ständiges Jesusgebet ein inneres, spirituelles Leben zu erlernen und einzuüben. Damit wird auch schon auf die inneren Zusammenhänge von Atem und ständigem Jesusgebet hingewiesen.

\section{Gebet und Atem}

Die Mönche in den Klöstern am Berg Athos pflegten das Jesusgebet sehr intensiv. Ihre Frömmigkeit, der Hesychasmus, hat tiefe Wurzeln in der Spiritualität der Wüstenväter Ägyptens. Die hesychia gehörte zu ihren zentralen Gedanken. Hesychia ist ein terminus technicus und

8 Philokalie der heiligen Väter der Nüchternheit, 6 Bände, Würzburg ${ }^{22007, ~ B d . ~ 1, ~}$ $292 f$.

9 Kleine Philokalie, 90f, 108.

${ }^{10}$ Ebd., 109. 
heisst nicht einfach Ruhe oder Stille, sondern eine aus dem Gebet entstandene Herzensruhe, eine intensive meditative Gotteserfahrung und -begegnung. Das Verbum hesychazein bedeutet, in diesem Sinne die hesychia üben. Antonius pflegte, sich in der Wüste der Herzensruhe hinzugeben, sich vom Hören, Reden und Sehen zu distanzieren und sich allein auf Gott zu konzentrieren. Sein Zeitgenosse Arsenios unterrichtete seine Schüler mit den drei kurz formulierten Prinzipien: »Fliehe, schweige, ruhe " (pheuge, siōpa, hesychaze) ${ }^{11}$, d.h. fliehe die Welt, übe das Schweigen und pflege die Herzensruhe. Der bereits genannte Asket Evagrius Ponticus sah als Ziel der Askese, dem Geist eine «unerschütterliche Ruhe» zu vermitteln.

Der Hesychasmus, der sich im byzantinischen Mönchtum im 12.-16. Jahrhundert aus diesen Ansätzen entwickelte, stellte die ausschliessliche Konzentration auf Gott in den Mittelpunkt der Spiritualität und wies dem Jesusgebet eine entscheidende Rolle auf diesem Weg zu. Zu den bedeutendsten Theoretikern dieses Weges gehörte Nikephoros der Einsiedler im 13. Jahrhundert. Er stammte aus Italien, konvertierte vom römisch-katholischen Glauben zur Orthodoxie und lernte als Mönch in den Klöstern am Berg Athos den Hesychasmus kennen und schätzen. Er sammelte viel Material zum Thema der geistlichen Nüchternheit und dem Gebet und lehrte, dass der Asket, nachdem er alle irdischen Dinge hinter sich gelassen habe, den Weg der Wüstenväter gehen soll. Er orientierte sich vor allem an Antonius und Johannes Klimakus im 6. Jahrhundert, machte sich Gedanken über die Gebetsmethode, und schrieb in seinen Anleitungen, welche Techniken und Gebetsübungen man anwenden solle, welche Körperhaltung und welche Atemtechnik erforderlich seien: "Setze dich, $[\ldots]$ ziehe deinen Atem durch die Nase ein $[\ldots]$. Zwinge den Atem, im Augenblick des Einatmens zum Herzen hinabzusteigen. Wenn du ihn dort eine Welt festhältst, wirst du die Freude spüren, die daraus folgt. [...] Deine einzige Tätigkeit und Betrachtung sei das Herzensgebet `Herr Jesus Christus, Sohn Gottes, erbarme dich meiner. « ${ }^{12}$ Nikephoros empfahl, neben dem gemeinsamen monastischen Gottesdienst diese Gebetspraxis individuell zu pflegen, unerlässlich sei es aber, sich von einem zuverlässigen Meister, einem geistlichen Vater (patēer pneumatikos) dazu anleiten lassen. Bei den Worten «Herr Jesus Christus, Sohn Gottes» pflegte man einzuatmen, bei den Worten "Erbarme dich meiner" atmete man aus.

Gregor vom Sinai (1255/65-1346) entwickelte diese Gedanken weiter und wurde $\mathrm{zu}$ einem der angesehensten Theoretiker des

${ }_{11}$ Abbas Arsenios, Apophthegma 40, Weisungen derVäter, 25.

${ }^{12}$ Kleine Philokalie, 130f. 
Gebets in der orthodoxen Kirche. Er empfahl, in leicht gebeugter Stellung auf einem Schemel zu sitzen, ruhig und gleichmässig zu atmen und im Rhythmus des Atems das Jesusgebet zu beten, und zwar solange, bis es so verinnerlicht und sozusagen zur zweiten $\mathrm{Na}-$ tur des Betenden geworden ist. Das Beherrschen des Atems ist von grosser Wichtigkeit. Wer aufgeregt ist, ist häufig »ausser Atem«. Der Hesychasmus will erreichen, dass der Beter völlig frei ist von allen weltlichen Sorgen, Aufregungen, vom Herumrennen und Rotieren. Statt dessen soll man sich vom Alltäglichen distanzieren, sich auf Jesus Christus konzentrieren und die Herzensruhe pflegen. Gregor unterscheidet dann verschiedene Stufen der Gebetsintensität. Ziel ist es, dass das Ich und das Gebet miteinander eins werden. Nikephoros, Gregor und zahlreiche weitere Mönche waren Mystiker: Das intensive Beten des Jesusgebets führte sie zu Lichtvisionen und zur Unio mystica.

Symeon von Thessaloniki (gest. 1429), Metropolit dieser Stadt in politisch äusserst schwieriger Zeit - die Eroberung der Stadt durch die Osmanen stand unmittelbar bevor -, war der Meinung, dass das Jesusgebet nicht nur eine Angelegenheit von Mönchen und Einsiedlern sei und nicht nur in den Klöstern oder Einsiedeleien gepflegt werden solle, sondern auch von den Weltpriestern und den Laien intensiv gebetet werden soll. Welche Bedeutung das Jesusgebet für ihn hatte, zeigte er in einer kleinen Schrift "Über das heilige und vergöttlichende Gebet - darüber, was dieses Gebet alles ist«, das in die Philokalie, in die Sammlung der Schriften zur geistlichen Nüchternheit und zum Gebet, die im 18. Jahrhundert in den Klöstern am Berg Athos entstand, aufgenommen wurde. Nach Symeon von Thessaloniki ist das Jesusgebet "sowohl Flehen als auch Bekenntnis des Glaubens; es vermittelt den Heiligen Geist, verschafft göttliche Gaben, reinigt das Herz, vertreibt die Dämonen, lässt Jesus Christus in einem wohnen, ist eine Quelle von geistlichen Erwägungen und göttlichen Gedanken, bedeutet Erlösung von Sünden, ist eine Heilungsstätte für Seele und Leib, verschafft göttliche Erleuchtung, lässt das Erbarmen Gottes hervorsprudeln, verleiht unter Demut göttliche Offenbarungen und ist das einzig Heilbringende, da es in sich den heilbringenden Namen unserer Gottes trägt. ${ }^{13}$

Die Hesychasten mit ihrer Gebetspraxis und ihrer Mystik waren in der byzantinischen Kirche heftig umstritten und auch viel Spott ausgesetzt. Wegen ihrer Gebetshaltung wurden sie auch "Nabelschauer" (omphaloskopoi) genannt. Ihre mystische Einigung mit Christus und die damit verbundenen Lichtvisionen wurden immer

${ }^{13}$ Philokalie der heiligen Väter, Bd. 5, 377. 
wieder in Frage gestellt. Kann der Mystiker überhaupt etwas von Gott sehen, und was erlebt er eigentlich in seiner Gottesschau? Ist das Licht, das der Mystiker sieht, etwas, das zu Gottes Wesen (ousia) gehört und somit etwas Ungeschaffenes? Oder ist dieses Licht etwas Geschaffenes, ein Stück der Schöpfung Gottes und somit nicht etwas vom Wesen Gottes? Die Antwort des Hesychasten Gregor Palamas (1296-1359) lautete: Der Mystiker sieht nicht Gott an sich, nicht ein Stück des Wesens Gottes. Was er sieht, ist aber auch nicht einfach etwas Geschaffenes. Der Mystiker sieht Gottes ungeschaffene Energien, also etwas, das von Gott ausgeht, aber doch nicht Schöpfung ist. Gottes Energien verhalten sich zu Gott wie die Strahlen der Sonne zur Sonne. Die Sonnenstrahlen können wahrgenommen werden, in die Sonne selber aber kann man nicht blicken. Diese Theologie war damals sehr umstritten und wurde sehr heftig bekämpft. Doch zwei Kirchensynoden in Konstantinopel $(1341,1351)$ erklärten die Theologie des Gregor Palamas als rechtgläubig, verurteilten die Antipalamiten, und Palamas wurde bald nach seinem Tod 1386 heiliggesprochen.

Die Nachwirkungen der hesychastischen Spiritualität waren sehr gross, nicht nur in den Klöstern am Berg Athos, sondern überhaupt in den orthodoxen Kirchen des byzantinischen Reiches, Serbiens, Bulgariens, Rumäniens und Russlands. Insbesondere in Rumänien und Russland erfuhr der Hesychasmus im 19. Jahrhundert eine eindrückliche Blütezeit. Eine ganze Reihe von geistlichen Vätern verschiedener Klöster, die das Jesusgebet und die hesychastische Askese und Mystik lebten, wurden zu begnadeten Seelsorgern unter der Bezeichnung "Starzen«. Starez heisst eigentlich Greis, entspricht dem griechischen gerōn, und meint einen erfahrenen Mönch und Lehrer, der Novizen auf dem Weg der Askese anleitet. Die Kraft des Jesusgebets und die Mystik gaben den Starzen, wie sie selber bezeugen, innere Ruhe und Gelassenheit, grenzenlose Freude, tiefe Liebe $\mathrm{zu}$ Gott und führten die Starzen zu sehr guter Menschenkenntnis. Bisher waren sie Führer und Seelsorger der jungen Mönche, welche in das geistliche Leben eingeführt werden wollten. Im Kloster Optina (Gouvernement Kaluga) und dann auch in weiteren russischen Klöstern erhielt das Starzentum eine neue Ausrichtung: Die Starzen wurden charismatische Seelsorger zunächst in der unmittelbaren Umgebung, dann auch für Menschen, die in grösserer Entfernung vom Kloster lebten. Ratsuchende und Notleidende kamen mit ihren Alltagssorgen zu ihnen, die mit ihrer Spiritualität, ihrer herausragenden Menschenkenntnis im seelsorgerlichen Gespräch und Gebet den richtigen Ton fanden und viel Wegweisendes 
vermitteln konnten. Immer mehr Bauern, Handwerker, Kaufleute, Adelige, Wissenschaftler und Philosophen, die zum Teil Wege von mehreren hundert Kilometern zurücklegten, kamen zu den Starzen.

Dostojewski und Tolstoi gehörten zu ihnen. Dostojewski schilderte in seinem Roman Die Brüder Karamasow (vor allem im 6. Buch) das Starzentum ausführlich, aber auch sehr eigenwillig und mit grosser künstlerischer Freiheit. Der Starez Zosima sollte künstlerisch überzeugen. Orthodoxe Theologen und Religionsphilosophen kritisierten ihn deswegen scharf. Die guten Mönche in diesem Roman, und insbesondere Starez Zosima, würden nicht dasselbe sagen, was die ebenfalls guten Mönche in den Klöstern am Berg Athos, in Russland, Griechenland und Bulgarien sagen. ${ }^{14}$ Auch das Jesusgebet, das in den Belehrungen des Starzen einmal genannt ist, hat Dostojewski stark verändert. Nach seiner Darstellung ermahnte der Starez zum Beten und sagte unter anderem: "Des weiteren behalte:Täglich und wann immer es dir möglich ist, wiederhole im Herzen: >Herr erbarme dich aller, die heute vor Deinen Thron getreten sind. $\ll^{15}$ Aus dem Jesusgebet mit seiner Bitte um Gottes Erbarmen für den Betenden wurde bei Dostojewski eine Fürbitte für die soeben Verstorbenen.

\section{Das Jesusgebet in den Christenverfolgungen der Sowjetzeit}

In der atheistischen, religionsfeindlichen Sowjetunion, in der Religion als Opium für das Volk galt und mit allen Mitteln, zeitweise auch blutig, bekämpft wurde, konnte der christliche Glaube oft nur im Verborgenen gelebt werden. Der russische Mönch Sergej Nikolaevič Bol’šakov, selbst ein tief gläubiger Bekenner des orthodoxen Glaubens, ging Geistlichen und Laien, die das Jesusgebet übten, nach, befragte sie nach ihrem geistlichen Leben und vermittelte in seinem

\footnotetext{
${ }^{14}$ Konstantin Leontjew, Unsere neuen Christen, zit. aus: Nicolai von Bubnoff, Russische Religionsphilosophen. Dokumente, Heidelberg 1956, 97. Im Brief an seinen Verleger Nikolaj Ljubimov hatte Dostojewski geschrieben: "Ich hege ja wohl die gleichen Gedanken, die er [der Starez Zosima, E.B.] ausspricht [...]. Er aber konnte weder andere Worte gebrauchen, noch sich in einem anderen Geiste ausdrücken, sondern nur so, wie ich es ihm in den Mund gelegt habe. Es wäre sonst keine künstlerisch gesehene Gestalt entstanden. "Zitiert aus: F. M. Dostojewski, Die Urgestalt der Brüder Karamasoff. Dostojewskis Quellen, Entwürfe und Fragmente. Erläutert von W. Komarowitsch, München 1928, 570.

${ }^{15}$ Fjodor Dostojewskij, Die Brüder Karamasow. Aus dem Russischen von Swetlana Geier, Zürich 2003, Buch 6, Kap. 3g, 513.
} 
Büchlein »Auf den Höhen des Geistes. Gespräche eines russischen Mönchs über das Jesusgebet ${ }^{16}$ eindrucksvolle Berichte über seine Gespräche. Er zeigte, dass Mönche und Nonnen, aber auch Laien, die in diesen für die Kirche dramatischen und schmerzlichen Jahren unmittelbar nach der Revolution von 1917, in der Mitte der 1920er Jahre und am Ende der Stalinära in der ersten Hälfte der 1950er Jahre ihren Glauben lebten, aus dem Jesusgebet die Kraft für ihr Leben in schwerer Zeit schöpften.

$\mathrm{Zu}$ den eindrücklichsten Begegnungen gehörten die Zusammenkünfte mit einem Arzt Dr. Evgenij Rozov in Pskov im Westen der Sowjetunion im Jahre 1926. Als praktizierender Arzt in dieser altehrwürdigen Stadt betreute er auch die Mönche im dortigen Höhlenkloster. Der fünfzigjährige Rozov war ein ausgesprochen vergeistigter Mensch, der dem Reich Gottes und seiner Gerechtigkeit dienen wollte. Arme behandelte er unentgeltlich, wie es in der orthodoxen Tradition Heilige wie Kosmas und Damian oder Panteleimon getan hatten. Wie er die Kraft dazu finde, wollte Bol'šakov von ihm wissen, und er erhielt zur Antwort: »Das Wichtigste ist, den Frieden des Herzens zu erwerben. Wenn Sie ihn erworben haben, dann haben Sie in nichts einen Mangel, es wird ja gesagt: Erwirb den Frieden des Herzens und Tausende um dich herum werden gerettet werden. ${ }^{17} \mathrm{Um}$ die innere Ruhe und die Unabhängigkeit von dieser Welt zu erlangen, brauche es eine intensive geistliche Vorbereitung. Die Philokalie und die Aufrichtigen Erzählungen eines russischen Pilgers aus dem 19. Jahrhundert mit ihren zahlreichen Anweisungen zum geistlichen Leben hätten ihm die entscheidenden Impulse gegeben. Mit ihnen habe er sich im Jesusgebet eingeübt und damit viele Hilfe erfahren. Er habe sich darum bemühen müssen, aber mit den Jahren sei es ihm zur zweiten Natur geworden, wie ihm geraten worden war: "Im Gebet gehen Sie, wie in allem, massvoll vor. Alles kommt von selbst mit den Jahren, nur bemühen muss man sich. « ${ }^{18}$

Auch ein Gespräch mit dem Priestermönch Dorofej 1951 im hohen Norden Russlands ging von der Frage aus, wie man zum inneren Frieden kommen könne. In der Antwort wies Dorofej ebenfalls auf das Jesusgebet hin, und auch er sagte, dass es anfänglich viel Überwindung und inneren Zwang brauche, die Askese mit der

\footnotetext{
${ }^{16}$ Sergej Nikolaevič Bolšakov, Auf den Höhen des Geistes. Gespräche eines russischen Mönchs über das Jesusgebet, Wien 1976; Neuausgabe mit dem Untertitel "Beter des Jesusgebetes in den Klöstern und in der Welt«,Vier-Türme-Verlag, Münsterschwarzach 2012. Ich zitiere im Folgenden aus der älteren Ausgabe.

17 Ebd., 45.

${ }^{18}$ Ebd., 42 f.
} 
Zeit aber immer leichter werde und schliesslich fliesse das Jesusgebet in einen ein wie ein Bach, man werde wie eine blühende Linde. Dank des Jesusgebetes habe er die Schrecken der Religionsverfolgungen in der Stalinzeit aushalten können. Er erzählte: "Wir wurden in die Verbannung geschickt. Ich wollte nicht, aber man musste sich dreinfügen. Nun, als man uns wirklich hierher deportierte, da ging ich heiter, die anderen aber weinten. Über allem ist der Wille Gottes. Wenn du den Willen Gottes mit der Güte Deines Herzens und in Liebe annimmst und nicht von dir selbst weiss Gott was für Wunderdinge erwartest, dann erst kommst du zur Ruhe. [...] Ohne die Ruhe werdet ihr allerdings nicht zum reinen Gebet kommen." Das reine Gebet war für Dorofej das Jesusgebet. "Wer sich im wahren Gebet betätigt, der ist ruhig im Schatten des Herrn." Diese innere Ruhe gab Dorofej die Kraft, das sehr harte, entbehrungsreiche Leben in derVerbannung auszuhalten. ${ }^{19}$

Als sich Bolšakov im Oktober 1951 im Kloster Dionysiou am Berg Athos aufhielt, erklärte ihm ein Mönch, dass das Jesusgebet immer und in jeder Situation gebetet werden könne, »zu Hause, auf der Strasse, auf der Reise, im Gefängnis, im Krankenhaus«. Allerdings brauche es eine lange und sorgfailtige Phase des Erlernens und des Einübens. »Schliesslich kannst du es mit deinem Atem und mit deinem Herzschlag vereinen. [...] Dann kommt in deinem Geist dieses Gebet von selbst, wie ein Bach: ob du nun gehst oder arbeitest oder schläfst $[\ldots]$ Dein ganzes Leben wird zum Gebet. ${ }^{20}$

$\mathrm{Zu}$ den Starzen, die in der Sowjetzeit unter sehr schwierigen Umständen gelebt und Schriftliches hinterlassen haben, gehört Nikon Vorobev (1894-1963). Er stammte aus dem Gouvernement Tver, studierte Psychotherapie in Petrograd und übte seinen Beruf eine Zeitlang aus. 1931, in den Jahren des schlimmsten Massenterrors in der Ära Stalins, in denen es ungewöhnlichen Mut brauchte, sich öffentlich zur Kirche zu bekennen, liess er sich zum Mönch weihen, zwei Jahre später empfing er die Priesterweihe. Bald darauf wurde er verhaftet. Die Behörden warfen ihm vor, ein subversives Element der sowjetischen Gesellschaft zu sein.Vier Jahre verbrachte er in den Straflagern des Archipel GULAG in Sibirien. 1937, als Tausende von Geistlichen erschossen wurden, kam er frei. Man brauchte ihn wegen seiner medizinischen Kenntnisse und beschäftigte ihn als Hilfskraft in einer Arztpraxis. Nachdem gegen Ende des Zweiten Weltkrieges die Religionspolitik gelockert worden war, konnte Nikon wieder als Priester wirken. Er arbeitete im Gouvernement Kaluga. Wie

19 Ebd., 7.

${ }^{20}$ Ebd., 14. 
viele andere Menschen in seiner Umgebung hatte er die Religionsbedrückungen und -verfolgungen, Gefängnis, Lager, Irrenanstalten, Misshandlungen, Menschenrechtsverletzungen erlitten und wurde mit seinen geistlichen Erfahrungen ein charismatischer Seelsorger für Leute, die Ähnliches durchgemacht hatten. Man habe in seiner Gegenwart immer wieder ein Gefühl unbeschreiblicher Freude erlebt, wurde berichtet. Nikon war als geistlicherVater von Menschen, die selber sehr viel gelitten hatten, ausserordentlich geschätzt.Viele, auch Kommunisten, suchten ihn im Geheimen auf. Eine grosse Ausstrahlung übte Starez Nikon mit seinen Briefen aus. Kam er auf das Gebet zu sprechen, empfahl er in der Tradition der orthodoxen Kirche jeweils das Gebet des Zöllners »Herr, sei mir Sünder gnädig" (Luk 18,13) und das Jesusgebet zu beten.

So riet er 1954, ein Jahr nach Stalins Tod und zwei Jahre vor der Entstalinisierung, einer Mutter auf ihre Fragen hin, sich am Zöllner im Gleichnis Jesu ein Beispiel zu nehmen. »Der Herr hat mit dem Gleichnis vom Zöllner und Pharisäer gezeigt, wie und mit welcher seelischen Haltung man beten soll und wie man nicht beten soll (pharisäische Einstellung). Nach der Ankunft des Erlösers und nach seinem Leiden ist das Gebet des Zöllners von den heiligen Vätern durch das Jesusgebet ersetzt worden: >Herr Jesus Christus, Sohn Gottes, erbarme dich meiner.< Der Sinn ist ein und derselbe. $\|^{21}$ In einem anderen Brief, ebenfalls aus dem Jahr 1954, schrieb er seinen Lesern von der christlichen Hoffnung und riet, sich nicht auf irgendwelche guten Werke, sondern allein auf die Gnade Gottes zu stützen: "Worauf können wir hoffen? Einzig nur auf Gottes Gnade. Vergessen wir alle unser guten Taten, und rufen wie der Zöllner im Tempel aus: `Gott, sei uns Sündern gnädig!‘ Und da der Zöllner allein durch dieses Gebet von allen Sünden befreit wurde, können auch wir glauben, dass sich der Herr unser erbarmt. So lehrt uns der Herr Jesus Christus: Betet und hofft auf Gottes Barmherzigkeit. Keine Krankheit hindert uns daran, uns wenigstens ein paar Mal am Tag mit Reue im Herzen an den Herrn zu wenden. $\|^{22}$

Der Rat, ein kurzes Gebet ständig zu wiederholen, gehörte zu den häufig ausgesprochenen Empfehlungen Nikons. Dies konnte das Jesusgebet sein, aber auch das Gebet des Schächers am Kreuz: "Jesus, denk an mich, wenn du in dein Reich kommst." Nikon riet in einem Brief 1958: „Um dies zu verstehen, liebe M., um demütig zu werden und dich in Gottes Hände zu begeben, wiederhole un-

\footnotetext{
${ }^{21}$ Igumen Nikon, Briefe eines russischen Starzen an seine geistlichen Kinder. Aus dem Russischen von Lorenzo Amberg, Freiburg i.Br. 1988, 32f.

22 Ebd., 34.
} 
ablässig das Gebet: Herr, dein heiliger Wille geschehe, tu mir, was dir beliebt; lass nur nicht zu, dass ich gegen dich aufbegehre, und rette mich. ${ }^{23} 1954$ schrieb Nikon an eine Frau, die ihn um Ratschläge für ihre Gebetspraxis gebeten hatte. »Der Zöllner belehrte nicht, sondern sprach mit Zerknirschung >Gott, sei mir Sünder gnädig!«« Dies sei die rechte Gebetshaltung. »Erst wenn die Haltung des Zöllners auf den ganzen Menschen übergreift, kann sich in uns die $>$ Kraft Gottes` entfalten und wir werden aus Ägypten ins Gelobte Land hinausgeführt. «24 1963, also mitten in der Phase der administrativen Einschränkungsmassnahmen Nikita Chruschtschews gegen die Kirchen, wandte sich Starez Nikon an eine Frau, der Glaubenszweifel zu schaffen machten: Wenn Glaubenszweifel auftreten, "sprechen Sie unablässig die Worte >Herr, erbarme dich!^ oder das Jesusgebet», und wenn man in einen Zustand völliger seelischer Erkaltung gerate, müsse man unbedingt die Gebetsregel erfüllen - trotz Kälte, Zerstreuung, usw. ${ }^{25}$

Nikon wie auch andere Starzen erwiesen sich als sehr feinfühlige Seelsorger. Sie schrieben keine Bücher und Abhandlungen. In ihren Briefen gehen sie sehr tief auf die einzelnen Menschen ein und formulieren dabei auch Vieles, das andern Menschen in ähnlichen Nöten hilfreich sein kann.

Wie hilfreich das Jesusgebet in Extremsituationen des Lebens sein kann, bezeugt die russische Philosophin Tatjana Goričeva in einem ihrer Bücher. Tatjana Goričeva wurde 1947 in Leningrad geboren, wuchs in atheistischen Verhältnissen auf, studierte Philosophie und Radiotechnik und wurde mit 26 Jahren Christin. Es waren die Jahre eines religiösen Aufbruches in der Breschnew-Zeit (1965-1981). Allenthalben entstanden Dissidentenbewegungen. Sie betrafen Politik, Wissenschaft, Kunst und Religion, äusserten sich in geheimen $\mathrm{Zu}-$ sammenkünften und Seminaren sowie in Untergrundpublikationen (samizdat $=$ Selbstverlag). Die sowjetischen Behörden reagierten sehr nervös. Die Exponentinnen und Exponenten dieser Bewegungen wurden verhaftet, nach Sibirien in die Verbannung geschickt, in Nervenheilanstalten eingewiesen oder sogar aus der Sowjetunion ausgebürgert. Tatjana Goričeva schloss sich nach ihrer Bekehrung zum orthodoxen Glauben diesen Bewegungen an, gründete selber die erste Frauenbewegung in der Sowjetunion, organisierte religiöse Seminare und gab zwei Untergrundzeitschriften heraus. Sie wurde verhaftet und vom Staatssicherheitsdienst KGB dermassen schikanös

${ }^{23}$ Ebd., 38 .

${ }^{24}$ Ebd., 43.

${ }^{25}$ Ebd., 73 
verhört, dass sie sich weigerte, dieser Behörde Auskünfte zu geben. Sie habe jedes Gespräch mit dem KGB konsequent abgelehnt, erzählte sie später. Sie erfuhr die Verhöre des KGB ähnlich wie die Asketen der ägyptischen Wüste die Versuchungen durch das Böse und die Dämonen. Und sie reagierte entsprechend darauf: mit dem Gebet, vor allem dem Jesusgebet. »Ich betete still für mich. Besonders das Jesusgebet half mir: >Herr Jesus Christus, Sohn Gottes, erbarme dich meiner, der Sünderin.< Dieses Gebet schuf ein undurchdringliches Feld um mich herum. Dank dieses Gebets fühlte ich mich völlig geschützt, hinter welchen Wänden ich auch war und in welchen Verhältnissen ich mich auch befand. ${ }^{26}$ Nach zahlreichen Verhören und Aufenthalten in Gefängnissen wurde Tatjana Goričeva 1980 aus der Sowjetunion ausgebürgert; Ende Juli 1980 traf sie in Wien ein und lebt seither im Westen.

\section{Das Jesusgebet im Alltag}

Wie wir gesehen haben, ist das Jesusgebet in der monastischen Tradition der späten Antike und des Mittelalters in der orthodoxen Kirche entstanden, wurde vor allem von Einsiedlern, von Mönchen und Nonnen gebetet, doch es wurde auch immer wieder den Gemeindepriestern und den Laien empfohlen. Erzbischof Paul von der finnischen orthodoxen Kirche (Paavali Olmari, 1914-1987) legte das Jesusgebet den orthodoxen Gläubigen für die Bewältigung des Alltagslebens mit seinen vielfältigen Herausforderungen nahe. In seinem Büchlein Unser Glaube, das sich an ein breites Publikum wendet, nannte er das Jesusgebet das vollkommenste Gebet, da es alles Wichtige, das ein Gebet ausmacht, in kürzester Form enthält, die Inkarnation, die Dreieinigkeit, die zwei Naturen Christi, aber auch die Sünde des Menschen und seine Bitte um Gottes Erbarmen. "Wenn wir die Worte `Herr Jesus Christus, Sohn Gottes` sagen, bekennen wir, dass unser Heiland beides ist, Mensch und Gott. Den Namen Jesus erhielt Er von Seiner Mutter als menschliches Wesen, während die Worte >Herr` und >Sohn Gottes` auf Jesus als Sohn Gottes hinweisen. Die andere Grundwahrheit unseres christlichen Glaubens, die heilige Dreifaltigkeit, ist ebenfalls in unserem Gebet enthalten. Wenn wir uns an Jesus als Sohn Gottes wenden, ist nicht nur Gott der Vater mit eingeschlossen, sondern auch der Heilige

\footnotetext{
${ }^{26}$ Tatjana Goritschewa, Von Gott zu reden ist gefährlich. Meine Erfahrungen im Osten und im Westen, Freiburg i.Br. ${ }^{13} 1984,12$.
} 
Geist; denn der Apostel sagt: >Niemand kann sagen: Herr ist Jesus, ausser im Heiligen Geist (1. Kor 12,3). « $\mathbb{1}^{27}$

Erzbischof Paul erklärt weiter: Man kann zwei Teile im Jesusgebet unterscheiden, im ersten Teil die Anrufung und den Lobpreis Gottes, im zweiten Teil den Hinweis auf die Demut und die Busse des Menschen, seine Bitte um Trost und Hilfe. Das Jesusgebet soll ständig wiederholt werden, wie es auch schon die Wüstenväter im ersten Jahrtausend gelehrt und vorgelebt hatten. Dies ist auch dem heutigen Menschen in seinem Alltag mit seinen vielen Herausforderungen und Anstrengungen möglich: "Bei der Arbeit und der Ruhe, zu Hause und auf Reisen, allein oder unter Menschen, immer und überall wiederhole in deinem Geist und Herzen den süssen Namen des Herrn Jesu Christi, indem du die Worte sprichst: Herr Jesus Christus, Sohn Gottes, erbarme dich über mich Sünder. $\|^{28}$ In seinem Kapitel über die Gebetspraxis wird Erzbischof Paul sehr konkret. Man tut vieles gewohnheitsmässig und übt im Laufe des Tages auch zahlreiche mechanische Tätigkeiten aus, dies beginnt schon nach Tagesanfang: Waschen, Anziehen Frühstücken, usw. »Das ist eine Zeit, in der unsere Gedanken frei sind, die Worte des Gebets $\mathrm{zu}$ wiederholen. ${ }^{29}$ Hier könnte man das Jesusgebet einbauen. Wenn wir uns auf nicht-mechanische Arbeiten konzentrieren müssen und dies die ganze Aufmerksamkeit erfordert, so gibt es immer wieder Augenblicke der Entspannung, in denen man das Jesusgebet beten kann. "Wenn wir uns zur Gewohnheit machen, den Namen Jesus Christus jeweils auch nur eine halbe Minute zu wiederholen, [...] dann wird die Erinnerung an Gottes Gegenwart wie ein inneres Strömen in unserer Seele sein «. Übt man das Jesusgebet regelmässig, so werden wir "bewahrt bleiben vor jenem Leiden, das man heute Stress nennt und dessen Ursache darin liegt, dass wir mit allem auf einmal beladen sind. « $^{30}$

Auf die uralten Fragen "Wie soll man beten?« "Was soll man beten? « hat die orthodoxe Kirche viele Antworten bereit: die Psalmen aus dem Alten Testament, das Unser-Vater, die Gebete des eucharistischen Gottesdienstes, die Stundengebete, die Gebete, die den Gläubigen für alle Lebenssituationen in Gebetbüchern zur Verfügung stehen. Das Jesusgebet gehört in die reiche, vielfältige, spirituell tiefe Gebetstradition hinein. Der Gebetsruf »Herr Jesus Christus, Sohn Gottes, erbarme dich meiner", der aus verschiedenen

${ }^{27}$ Erzbischof Paul, Orthodoxe Kirche Finnland: Unser Glaube, Köln 1983, $92 f$.

${ }^{28}$ Ebd., 91.

${ }^{29}$ Ebd., 94.

${ }^{30}$ Ebd., $95 f$. 
Kurzgebeten entstanden ist und seit vielen Jahrhunderten vor allem von Mönchen, aber auch von Laien geschätzt und gepflegt wird, gehört zu den grossen und spezifischen Schätzen der orthodoxen Gebete. Es ist kurz, prägnant, kann im Rhythmus von Atem, Herzschlag, einförmiger Handarbeit, vieler Alltagsverrichtungen gebetet werden; es kann geradezu zur zweiten Natur des Menschen werden, und es erweist sich in Extremsituationen des Lebens, zum Beispiel in Glaubensverfolgungen, als sehr hilfreich, worüber es viele Zeugnisse gibt. Inhaltlich enthält es die Anrufung Christi und die Bitte um sein Erbarmen. Erzbischof Paul von der Finnischen Orthodoxen Kirche bringt es auf den Punkt, wenn er sagt, es sei das vollkommenste Gebet, das alles für den Glauben Wichtige enthält: die Menschwerdung Gottes in Jesus Christus, die Dreieinigkeit Gottes, die beiden Naturen Jesu Christi, die Sündhaftigkeit des Menschen und seine Bitte um das Erbarmen Gottes. Es gibt bestimmte Gebetsmethoden und -techniken, doch die grossen orthodoxen Beter betonen, dass das rechte Beten des Jesusgebets nicht eine Frage der Technik ist, sondern eine Gnade Gottes. Gebetstheologie ist Gnadentheologie.

— Prof. Dr. Erich Bryner ist Titularprofessor für osteuropäische Kirchengeschichte an der Theologischen Fakultät der Universität Zürich. 